\title{
Headaches in the Elderly Population
}

\author{
Salvatore Caratozzolo*, Elisa Pari, Elisabetta Venturelli, Fabrizio Rinaldi, Chiara Mancinelli, Paolo Liberini, \\ Renata Rao and Alessandro Padovani \\ Department of Clinical and Experimental Sciences, University of Brescia, Italy
}

Submission: March 10, 2017; Published: May 12, 2017

*Corresponding author: Salvatore Caratozzolo, Resident in Neurology, Neurology Unit-Department of Clinical and Experimental Sciences, University of Brescia -P.le Spedali Civili, 125123 Brescia, Italy, Tel: +39-393 0406304; Email: salvatore.caratozzolo@hotmail.com

\begin{abstract}
Background: Headache in community-living adults aged more than 65 years old is the 10th most common reported symptom in women and the $14^{\text {th }}$ most common in men. Although the prevalence of headache declines with age, approximately $10 \%$ of women and $5 \%$ of men, 70 years old aged, experience severe recurrent or constant headaches. Much less is known about the evolving clinical profile of migraine over life span. Present study aimed to investigate different type of headaches in elderly people and was carried out on a group of patient over 60 years of age.
\end{abstract}

Methods: 2032 consecutive patients assessed at the Headache Center of the Neurological ward of the Spedali Civili, Brescia, Northern Italy, between September 2011 and December 2013 were enrolled. Variables such as gender, years of headache duration, history of aura, headache characteristics, associated symptoms, presence of allodynia, headache frequency, headache days, and disability were collected. Medical history of these patients was also recorded. Headache diagnosis were made according to ICHD-2 criteria. Patients were stratified by age into 2 groups: group I (under 60 years old), group II (more than 60 years old).

Results: the diagnoses founded in patients aged more than 60 years old were: without aura migraine $(\mathrm{n}=23 ; 5,3 \%)$, with aura migraine $(\mathrm{n}=2 ; 11 \%)$ chronic migraine $(\mathrm{n}=11,15,7 \%)$, tension-type headache $(\mathrm{n}=1 ; 5,6 \%)$, chronic tension-type headache $(\mathrm{n}=4,10 \%)$, other headache $(n=6,35,3 \%)$. Without aura migraine is the most frequent form of headache in aging patients, while chronic migraine showed a stable incidence during age.

Discussion: Although the prevalence of headaches in elderly is relevant, few epidemiological studies have been conducted so far. In most epidemiological studies concerning the adult population, in fact, have been studied subjects with less than 60 years old. Studies of community-based headache population are warranted to define the influence of age on the full spectrum of migraine.

\section{Introduction}

Elderly subjects are among those most affected by pain due to a plethora of chronic conditions, end of life issues, lack of personal resources and are often helpless to improve their situation without medical support [1]. Pain in elderly is often chronic, non-malignant and is disproportionately undertreated. Some elderly believe that pain is part of aging and they must live with it; health care professionals often believe that less pain medication is indicated to treat chronic pain in elderly according to the rate of therapies for concomitant medical pathologies. Italy is one of the most aged country and it is estimated that more than $30 \%$ of Italian people will be older than 65 years old in 2050. Even if primary headaches usually reduce their frequency in lifetime, the $13 \%$ of female and $7 \%$ of male older than 65 years old reported a headache disorder, especially migraine form. In fact, in people older than 65 years was founded a one-year prevalence between 5 and 50\% of migraine; meantime $25-54 \%$ of aged more than 75 years old reported repetitive attacks in previous year [2,3]. Furthermore, headache is the $10^{\text {th }}$ symptom most frequently reported by 65 years older female and it is the 14 th symptom for male gender. Also in older patients' primary headaches are the most form of headache founded by clinicians using ICH-II [4]. Prevalence of migraine is age-related; reducing its incidence lifetime, particularly after 55-60 years old. However, $13 \%$ of female and more than $7 \%$ of men older than 65 years old suffer from migraine. Chronic migraine and tension-type headache in particular, does not change its frequencies with age. Primary headache incidence seems to decrease with age while secondary and nevralgic head pain show growing number of cases in elderly population. Headache in older people is difficult to diagnose for different reason:
A. Organic and psychiatric comorbidity
B. Polytherapy and drugs interactions
C. Decrease adherence in assuming therapy
D. Physiologic or pathologic differences in pain perception 
[5]. Even though this, literature lacks of epidemiological studies in general population on patients older than 65 years old with headache.

An Italian study evaluated 163 patients 60 years older using ICH-I criteria; primary headache was found in $93,3 \%$ of cases while only $6,7 \%$ had a diagnosis of secondary headache. As expected, it appears that patients suffers of without aura migraine (57\%), with aura migraine $(11.6 \%)$ and of episodic tension-type headache $(12.4 \%)$. In elderly population, clinical characteristics of the attacks often change. Sometimes they experience gradual attenuation of the autonomic symptoms and reduction of the duration and intensity of the headache. For that reasons, arises the need to start at Headache Center of the Neurological ward of the Spedali Civili, Brescia, a case-control study aimed to investigate the phenomenological aspects of headache in patients aged more than 60 years. Prevalence and incidence of migraine have been widely studied as mentioned above. Main purpose of the study is to determine the prevalence of the different form of primary headache in elderly patients and to assess if the clinical characteristic of headache changes in comparison with younger people. In this regard, the study describes a large population of patients referred to the Headache Center of Brescia divided by age. The whole population was evaluated to describe demographic and clinical characteristics of headache characteristics than were examined if diagnoses of headache change with age.

\section{Method}

2012 consecutive patients treated at the Headache Center of the Neurological ward of the Spedali Civili, Brescia, Northern Italy between September 2011 and December 2013 entered the study. These patients were evaluated through outpatient visit. Patients were excluded from the study if they had:

A. No headache history;

B. Headache attributed to trauma or accidents;

C. Neurological or systemic condition in with headache represented a cardinal symptom;

D. Headache onset for less than a month of enrollment in study;

E. Legal disputes related to headache;

F. Evaluation prior to the start of the database;

G. Cognitive Deficits for which they were not able to respond interview of the Headache Center Neurologists; 8. Language or intellectual barriers.

Demographic characteristics, family history of medical conditions, presence of comorbidities, characteristics of headache were investigated for all patients. Clinical evaluation included a careful analysis on the past use of symptomatic drugs and/or prophylaxis. Patient was educated to the use of a diary of headaches to report frequency, duration, intensity of pain and use of analgesics (especially their total number intake). Diagnoses of headache were placed in strict compliance with ICHD-2 criteria. For the first part of the study all patients (n $=2012$ ) were divided into seven diagnostic categories:

A. 1: without aura migraine;

B. 2: with aura migraine;

C. 3: cluster headache;

D. 4: tension-type headache;

E. 5: chronic migraine;

F. 6: chronic tension-type headache;

G. 7: other headache (including cranial neuralgia and headache that could not be classified).

We analyzed: age at onset of headache, years of disease, duration and intensity of attacks, associated symptoms, BMI, use of estrogen-progestin therapies, presence of others diseases (hypertension, hypercholesterolemia, diabetes mellitus, previous head injury) and menopause conditions. Patients were investigated about the characteristics of prodromal aura, frequency of headache in the last three months (days/ month), intensity (mild, moderate to severe) and type of pain (constrictive, oppressive, button, stabbing). Patients were stratified into two groups: group 1, under 60 years old and group 2 , more and equal than 60 years.

\section{Statistical Analysis}

All data analysis was performed using Statistical Package for the Social Sciences, SPSS vers. 21 (2013) The cohort is divided into two groups for analysis: group 1, under 60 years old and group 2, more and equal than 60 years old. Quantitative variables were expressed as a percentage or mean+standard deviation. Continuous variables were assessed using T-test analysis, differences between groups were tested using Student's $t$ test, $\mathrm{U}$ testing, parametric and non-parametric correlation test and $\chi$-Square Mann-Whitney test. The significance level was set at $\mathrm{p}<0.5$.

\section{Results}

The analyzed sample includes 2012 patients with headache (1520 females and 492 males). The diagnoses were made according to the ICHD-II criteria, assessed at the Headache Center of the Neurological ward of the Spedali Civili, Brescia with a clinical follow up of almost two years. The diagnoses founded were: migraine in 1279 (1028-migraine without aura, 83-migraine with aura and 148-combination of them); 201 patients suffered by chronic migraine; tension-type headache was diagnosed in 48 subject while 40 patients had chronic tension-type headache. Tension-type headache associated with episodic without aura migraine was found in 295 patients; tension-type chronic headache associated with without aura 
migraine was found in 67 patients while tension type chronic headache and migraine with and without aura in 45 patients; 25 subject was diagnosed with cluster headache, while other types of headache were found in 32 patients (Table 1). Without aura migraine was the most frequent pathology in our sample with an early onset age $(18,6+3,4$ mean age $)$ and with the characteristics that remain stable during age; with aura migraine showed a later onset $(21,1+4,4$ mean age $)$ as was also found in cluster headache $(23,8+5,3)$; tension-type headache, and in particular the chronic form, has a later onset compared to migraine $(29,8+11,0$ mean age for tension type-28,6+9,5 mean age for chronic migraine); high BMI, high blood pressure, sleep disorders, cigarette smoking and excessive consumption of caffeine, currently considered potential risk factors for progression of the disease have not shown a correlation with different types of headache; as expected chronic migraine patients have an increased number of years of the disease and a greater number of analgesic consumption/month than patients with episodic forms; discloses no statistically significant differences in chronic forms (chronic migraine and tension-type headache chronic) in years of schooling, employment and social status. According with the different age groups, patients aged less than to 60 years (Group 1) was composed by 1880 patients (93\%) while patients aged more or equal than 60 years (Group 2) was composed by 132 patients (7\%) (Table 2).

Table 1: Incidence of different diagnosis of headache in a population of 2012 patients evaluated in the Headache Centre of Spedali Civili di Brescia.

\begin{tabular}{|c|c|c|c|}
\hline Diagnosis & Female & Male & Total \\
\hline Without Aura Migraine & 766 & 262 & 1028 \\
\hline With Aura Migraine & 48 & 35 & 83 \\
\hline Cluster Headache & 4 & 21 & 25 \\
\hline Tension Type Headache & 34 & 14 & 48 \\
\hline Chronic Migraine & 165 & 36 & 201 \\
\hline Tension Type Chronic Migraine & 31 & 9 & 40 \\
\hline Other Headache & 21 & 11 & 32 \\
\hline $\begin{array}{c}\text { With and Without Aura } \\
\text { Migraine }\end{array}$ & 108 & 40 & 148 \\
\hline $\begin{array}{c}\text { Without Aura Migraine + } \\
\text { Tension Type Headache }\end{array}$ & 249 & 46 & 295 \\
\hline $\begin{array}{c}\text { Without Aura Migraine + } \\
\text { Tension Type Chronic Headache }\end{array}$ & 56 & 11 & 67 \\
\hline $\begin{array}{c}\text { With and Without Aura } \\
\text { Migraine + Tension Type } \\
\text { Chronic Headache }\end{array}$ & 38 & 7 & 45 \\
\hline $\begin{array}{c}\text { Total } \\
\text { (15iol }\end{array}$ & 1520 & 492 & 2012 \\
\hline
\end{tabular}

Table 2: Demographics characteristics of patients with different diagnosis of Migraine.

\begin{tabular}{|c|c|c|c|c|c|c|c|c|c|c|}
\hline & \multicolumn{2}{|c|}{$\begin{array}{c}\text { Without Aura } \\
\text { Migraine (1048 } \\
\text { patients) }\end{array}$} & \multicolumn{2}{|c|}{$\begin{array}{c}\text { With Aura Migraine } \\
\text { (83 patients) }\end{array}$} & \multicolumn{2}{|c|}{$\begin{array}{c}\text { Cluster Headache } \\
\text { (25 patients) }\end{array}$} & \multicolumn{2}{|c|}{$\begin{array}{l}\text { Tension-Type } \\
\text { Headache } \\
\text { (48 patients) }\end{array}$} & \multicolumn{2}{|c|}{$\begin{array}{c}\text { Chronic Migraine } \\
\text { (201 patients) }\end{array}$} \\
\hline & Means & SD & Means & SD & Means & SD & Means & SD & Means & SD \\
\hline Age & 37,1 & 25,4 & 35,8 & 28,9 & 38,0 & 29,8 & 36,4 & 27,5 & 41,6 & 29,8 \\
\hline Education & 11,6 & 3,2 & 11,9 & 3,5 & 11,3 & 2,8 & 10,9 & 2,7 & 10,7 & 3,1 \\
\hline $\begin{array}{l}\text { Age of } \\
\text { Onset }\end{array}$ & 18,6 & 3,4 & 21,1 & 4,4 & 23,8 & 5,3 & 29,8 & 11,0 & 28,6 & 9,5 \\
\hline $\begin{array}{l}\text { Years of } \\
\text { Headache }\end{array}$ & 19,1 & 5,4 & 16,1 & 3,2 & 16,5 & 2,9 & 8,1 & 2,9 & 24,2 & 11,0 \\
\hline $\begin{array}{l}\text { Days of } \\
\text { Headache/ } \\
\text { Month }\end{array}$ & 7,1 & 4,5 & 4,6 & 2,1 & 11,0 & 2,1 & 16,6 & 4,6 & 20,9 & 3,8 \\
\hline $\begin{array}{c}\text { Drugs } \\
\text { Intake (n) }\end{array}$ & 8,6 & 3,5 & 3,0 & 1,2 & 8,0 & 3,2 & 5,4 & 1,2 & 18,8 & 3,6 \\
\hline BMI & 23,3 & 8,9 & 24,6 & 7,7 & 22,9 & 6,5 & 23,9 & 5,9 & 23,7 & 7,1 \\
\hline
\end{tabular}

Patients older than 60 years reported more years of disease $(\mathrm{p}<0.001)$ and older age at onset of migraine without aura ( $P$ $<0.001$ ) compared to patients younger than 60 . In fact, there are no significant difference in duration, intensity and associated symptoms (nausea, vomiting, photophobia and phono phobia) in the two groups. Diagnosis in the group of patients with over and equal than 60 years are the following: Migraine without aura 22 patients $(15.6 \%$ of patients with this diagnosis in the age groups considered); Migraine with aura 2 patients ( $1.4 \%$ of patients with this diagnosis in the age groups considered); Chronic migraine 9 patients $(6.3 \%$ of patients with this diagnosis in the age groups considered); tension-type headache 15 patient $(10.5 \%$ 


\section{Open Access Journal of Neurology \& Neurosurgery}

of patients with this diagnosis in the age groups considered) (Table 3). As shown there are no differences migraine without aura incidence between the two groups. Chronic Migraine tends to remain over the years, while Tension Type headache seems to be more prevalent in the aging group $(\mathrm{p}<0.05)$ (Table 4).

Table 3: Mean Years of headache according with Age groups.

\begin{tabular}{|c|c|c|c|c|c|}
\hline & \multicolumn{2}{|c|}{ Age $<60$ years old $(1880-93 \%)$} & \multicolumn{3}{|c|}{ Age $>60$ years old $(132-7 \%)$} \\
\hline & Means & SD & Means & SD & $\mathbf{p}$ \\
\hline $\begin{array}{l}\text { Mean years of } \\
\text { Headache }\end{array}$ & 19.16 & 5.3 & 34.19 & 3.9 & 0.001 \\
\hline $\begin{array}{c}\text { Mean days of } \\
\text { Headache/month }\end{array}$ & 7.51 & 3.9 & 12.95 & 6.1 & NS \\
\hline $\begin{array}{l}\text { Mean number of } \\
\text { drugs intake }\end{array}$ & 8.23 & 3.2 & 11.61 & 4.7 & NS \\
\hline
\end{tabular}

Table 4: Incidence of different diagnosis of headache in a group of patients aged more and equal than 60 years old.

\begin{tabular}{|c|c|c|c|c|c|}
\hline \multirow[b]{2}{*}{ Diagnosis } & \multicolumn{2}{|c|}{ Age $<60$ years old } & \multicolumn{2}{|c|}{ Age $\geq 60$ years old } & \multirow[b]{2}{*}{ p. } \\
\hline & $\mathrm{n}$ & $\%$ & $\mathrm{n}$ & $\%$ & \\
\hline $\begin{array}{l}\text { Without Aura } \\
\text { Migraine }\end{array}$ & 326 & 17.2 & 22 & 15.6 & NS \\
\hline With Aura Migraine & 59 & 3.1 & 2 & 1.4 & NS \\
\hline Cluster Headache & 41 & 2.1 & 1 & 0.8 & NS \\
\hline $\begin{array}{l}\text { Tension Type } \\
\text { Headache }\end{array}$ & 104 & 5.5 & 15 & 10.5 & 0.05 \\
\hline Chronic Migraine & 121 & 6.4 & 9 & 6.3 & NS \\
\hline Total & 651 & & 67 & & \\
\hline
\end{tabular}

\section{Discussion}

In our data, tension-type headache is less frequent than migraine in patients over 60 years old; chronic migraine is maintained stable with age as expected for chronic form of migraine. We have found no differences in clinical characteristic of migraine. This is in contrast with what emerged from the work of Bigal [6] and Kelman [7] which explained how clinical features of migraine in the elderly present some differences from the earlier age, in particular, associated with vegetative symptoms (photo-phono phobi, nausea and vomiting). As well as in the work of Wang of 2000 [8], our data confirm that chronic migraine and chronic tension-type headache do not present peculiar characteristics in elderly than to younger individuals. Both headaches prefer female gender and present their debut several years before. Migraine, upon becoming chronic, tends to remain unchanged over time and last up to geriatrics. Unlike cited works, migraine does not seem to become less intense and less severe over the years in the sample of patients studied. It confirms the data that the prevention therapy is associated with a decrease of the frequency and intensity of attacks. The possible changes in frequency and characteristics of migraine attacks needs some interesting questions. There are patients undergoing changes through environmental factors in history of their disease? Can the current therapeutic strategies influence this process? We can accelerate through therapies preventing an evolution toward a form of migraine less disabling? The impression is that the characteristics of the attacks tend to be maintained over time. We must consider that patients that cater to a second level Headache Center have a more disabling pain than the general population.

\section{Conclusion}

Longitudinal population studies are the only way to assess the real evolution of migraine in years. However, the parameters studied are from a large cohort of patients and are representative of second level centers headaches. Although the prevalence of headaches in elderly is relevant, few epidemiological studies have been conducted so far. In most epidemiological studies concerning the adult population, in fact, have been studied individuals of age less than 60 years. The critical review of the literature shows that studies in this area are scarce and not with older patients involving the use of new classifications HIS. For that reason, it is important to continue to try to define the clinical spectrum and prognostic migraine according with the increasing age.

\section{References}

1. JCAHO Pain Assessment and Management (2000) An Organizational Approach. Oak Burton Terrace, Illinois, USA.

2. Herr KA, Mobily PR (1996) Pain management in alternate care settings. In: Ferrell BR \& Ferrell BA (Eds.), Pain in the Elderly. IASP Press, Seattle, USA, pp. 101-109.

3. Stovner LJ, Zwart JA, Hagen K, Terwindt GM, Pascual J (2006) Epidemiology of headache in Europe. Eur J Neurol 13(4): 333-345.

4. Headache Classification Committee of the International Headache Society (2004) The international classification of Headache disorders, $2^{\text {nd }}$ edition. Cephalalgia 24(suppl1): 1-160. 
5. Headache Classification Committee of the International Headache Society (1988) Classification and diagnostic criteria for headache disorders, cranial neuralgias and facial pain. Cephalalgia 8(suppl 7): 1- 96.

6. Marcelo E Bigal, Richard B Lipton (2006) Modifiable Risk Factors for Migraine Progression. Headache 46: 1334-1343.
7. Kelman L (2005) Validation of the classification of migraine without aura (IHS A1.1) proposed in ICHD-2. Headache 45(10): 1339-1344.

8. Juang KD, Wang SJ, Fuh JL, Lu SR, Su TP (2000) Comorbidity of depressive and anxiety disorders in chronic daily headache and its subtypes. Headache 40(10): 818-823.

\section{Your next submission with Juniper Publishers} will reach you the below assets

- Quality Editorial service

- Swift Peer Review

- Reprints availability

- E-prints Service

- Manuscript Podcast for convenient understanding

- Global attainment for your research

- Manuscript accessibility in different formats ( Pdf, E-pub, Full Text, Audio)

- Unceasing customer service

Track the below URL for one-step submission https://juniperpublishers.com/online-submission.php 